\title{
Accreditation in a differentiated duopoly
}

\author{
Sverre Grepperud ${ }^{a}$, Terje Andreas Mathisen ${ }^{b^{*}}$ and Pål Andreas Pedersen ${ }^{b}$ \\ ${ }^{a}$ Department of Health Management and Health Economics, University of Oslo \\ ${ }^{\mathrm{b}}$ Nord University Business School, NO-8049 Bodø, Norway \\ * Corresponding author: email: terje.a.mathisen@nord.no, phone: +47 75517637
}

Post print version of:

Grepperud S, Mathisen TA, Pedersen PA. Accreditation in a differentiated duopoly. Manage Decis. Econ. 2019;1-14. https://doi.org/10.1002/mde.3005

\begin{abstract}
Accreditation is increasingly important worldwide; however, some industries have higher accreditation rates than others. We suggest a duopoly model to discuss how market characteristics affect the incentive for firms to seek accreditation. The discussion relates to the effects accreditation might have on the costs and demands in the markets, the degree of product differentiation (addressing both substitutable and complementary goods), type of competition (various Cournot and Bertrand games) and welfare for society. It follows that markets with high accreditation rates are either characterized by fierce competition (price competition in substitutable goods) or by a high degree of coordination (complementarity).
\end{abstract}

Keywords: Accreditation, quality, quantity competition, price competition, product differentiation.

JEL classification: D43, L11, L15 


\section{Introduction}

Available mechanisms for informing consumers about quality include branding, experience, warranties, free trials, labelling and various quality disclosure institutions. Quality disclosure may take many forms and include sellers that report product attributes (self-disclosure ${ }^{1}$ ) and independent agencies (certifiers or accreditation bodies) that systematically measure and report quality (thirdparty verification) (Dranove and Jin, 2010). Third-party verification (accreditation or certification ${ }^{2}$ ) is typically a response when products have credence good attributes and may be of two types. A first type verifies product quality, either in terms of exact measurement or by exceeding a given level (product accreditation). ${ }^{3} \mathrm{~A}$ second type verifies that an organization is meeting certain input and process standards (process accreditation). Here, becoming accredited requires an organization to demonstrate that it employs a specific set of management practices, that it meets certain professional requirements, and/or fulfils certain pre-specified standards (Griffith, Knutzen, and Alexander, 2002). ${ }^{4}$

Accreditation is a growth industry, but its importance seems to vary across sectors. ISO standards have been around since 1987, and by 1995 ISO 9000 had been adopted by 101 countries as a national quality assurance standard (Anderson, Daly, and Johnson, 1999). According to Corbett et al. (2002), more than 500,000 certifications have been awarded worldwide. In the US, the industries with the highest number of ISO 9000 certificates are "chemicals", "industrial and commercial machinery" and "electrical equipment" (Corbett et al., 2002). In 2009, a total of 7,435 US institutions in higher education were accredited (Woolston, 2012) and there was growth in the proportion of accredited business education programmes from 11\% in 1988 to $42 \%$ in 2007 (Corcoran, 2007). The National Association for the Education of Young Children (NAEYC) currently accredits approximately 8,000 early care and education programmes throughout US with an equivalent number being in the process of seeking accreditation (Whitebook, Sakai, and Howes, 2004). Since 2000, over 350 international hospitals have been accredited, the total nearly tripling between 2007 and 2011 (Woodhead, 2013). Almost half of the health maintenance organizations in US had voluntarily applied for accreditation by 1998 (Jin, 2005). By 2003, approximately 85\% of US hospitals were

\footnotetext{
${ }^{1}$ When producers self-disclose quantifiable quality information, consumers might infer that such information can be verified by third-parties and is therefore trustworthy (Dranove and Jin, 2010).

${ }^{2}$ In this paper, we use "accreditation" and "certification" interchangeably.

${ }^{3}$ Examples of product accreditation are report cards and laboratory testing of product quality.

${ }^{4}$ Both accreditation and licensure establish minimum quality standards (input quality); however, licensure controls entry while voluntary accreditation does not.
} 
accredited (Sprague, 2005)..$^{5}$

Much of the literature on accreditation is descriptive, but some studies, especially on hospital accreditation, are concerned with output improvements from accreditation. When surveying this literature, Shaw (2001, 2003, 2006), Braithwaite et al. (2006) and Greenfield and Braithwaite (2008) conclude that there are no convincing studies that provide evidence on accreditation causing output improvements. Similar conclusions are reached by Griffith et al. (2002) and Barker et al. (2002). ${ }^{6}$ Xiao (2010) estimates a model to assess the effectiveness and the impact of the national accreditation system for childcare centres on consumer welfare and finds that on average consumers do not gain much information beyond what they infer from a firm's reputation. In a study on ISO 9000 certification, Terlaak and King (2006) find that certified organizations grow faster after certification and that operational improvements do not account for this growth.

The purpose of this paper is to analyse how market characteristics such as the degree of product differentiation and type of competition affect accreditation incentives. The identification of factors that incentivize firms to become voluntarily accredited is important for understanding why some sectors have higher accreditation rates than others and why, for a given sector, some firms voluntary seek accreditation while others do not. ${ }^{7}$ To address such questions, we apply a framework first used by Singh and Vives (1984) to analyse competition in a differentiated duopoly. This approach enables us to study accreditation incentives in markets where the goods both are substitutes or complements and where firms compete on price or quantity. We study both the case where the firms simultaneously choose accreditation and quantities (simultaneous Cournot), and the case where the accreditation decisions are taken first, followed by a quantity competition (two-stage Cournot). We follow the same procedure when analysing the cases of price competition. First we consider the possibility that the firms simultaneously choose whether to accredit or not at the same time as they decide prices (simultaneous Bertrand), and the case where the accreditation decisions are taken first, then the firms meet in a price competition (two-stage Bertrand).

Given product accreditation, consumers receive information about products that may improve matching and attract new customers, thus increasing the willingness to pay for accredited products.

\footnotetext{
${ }^{5}$ Recently, accreditation has become a requirement for reimbursement by public programs (Medicare and Medicaid) or become required by law (mandatory accreditation). Both France and Australia have moved to a process of mandatory accreditation for public hospitals (Mumford et al., 2015). The EU requires that companies that produce regulated products, such as medical devices, must adhere to ISO 9000 standards (Marquardt, 1992).

${ }^{6}$ There is some evidence that accreditation may lead to a change in internal processes. Chen et al. (2003) find that hospitals rapidly increase compliance with standards in the months prior to external assessments. In systematically reviewing accreditation research, Greenfield and Braithwaite (2008) studied possible impacts in 10 different areas and found consistent positive association for two areas (promoting change and professional development).

${ }^{7}$ The motives for hospitals to seek accreditation are discussed in Grepperud (2015).
} 
Additionally, firms may also invest in better product quality before seeking accreditation. Given process accreditation, becoming accredited confirms that certain standards are fulfilled (production process requirements), which again may raise expectations (and the willingness to pay) among consumers about quality improvements as well as creating beliefs about accredited firms doing better than non-accredited ones on average.

The literature mentions various types of accreditation costs. In addition to audit fees, there are costs associated with (i) consulting and guidance, (ii) documenting production processes, (iii) training of staff, and (iv) changing production processes (Corbett et al., 2002). Some argue that such costs envisage economics of scale properties that can be substantial, especially when outside consultants perform much of the work (Anderson et al., 1999; Ferguson, 1996; Shapiro, 1986). ${ }^{8}$ Others argue that accreditation also may lead to higher productivity and lower production costs due to improved processes causing a better use of resources and lower service failure (Motwani, Kumar, and Cheng, 1996). ${ }^{9}$

Based upon the reasoning above, we assume that firms that become accredited, ceteris paribus, will increase the willingness to pay for own products. Customers are willing to pay higher prices since accreditation (wrongfully or not) provides assurance that the products have improved in quality. This increase in demand represents an opportunity for firms to derive benefits in terms of increased sales, improved market coverage and higher price premiums. Despite its generality, this assumption seems both intuitive and reasonable in the sense that it captures the essence of consumers' understanding of the functioning of accreditation. Furthermore, we assume that becoming accredited (meeting the accreditation standards) may both incur costs and save costs for accredited firms.

As accreditation is a part of the competitive strategies of firms, affecting both costs and market demands, our analysis has some similarities with the advertisement literature [see e.g. a review by Bagwell (2007)]. Hattori and Higashida (2012) discuss possible welfare effects from misleading (persuasive) advertising in a two-firm model with linear demand functions, cost functions being quadratic in advertising, and where the firms supply substitutes. A two-stage Bertrand model is analysed where firms choose their advertising levels before meeting in price competition and where more intensive advertising increases own demand as well the rival's demand. An important finding is

\footnotetext{
${ }^{8}$ Benson (1991) reports costs amounting to $\$ 500,000$ to prepare a 250 -person plant for an audit. A survey of larger ISO 9000 compliant firms found that the average one-time costs of seeking accreditation were $\$ 300,000$ with $10 \%$ paid to accreditation bodies, $20 \%$ to other external parties, and the balance associated with internal costs (Anderson et al., 1999). However, the same firms also reported on annual cost savings due to improved internal process equal to an average of $\$ 200,000$, suggesting an average payback period equal to 1.5 years.

${ }^{9}$ For acute care Australian hospitals, Mumford et al. (2015) find that the annual average financial expenditures over an accreditation cycle varied from 0.03 to $0.6 \%$ of the hospitals' total operating costs.
} 
that advertising is inefficiently excessive from a welfare point of view. Similar analyses are conducted by Glaeser and Ujhelyi (2010) and Matsumura and Sunada (2013) for the case of homogenous multifirm Cournot competition. Glaeser and Ujhelyi (2010) find that the increase in sales that follow from misleading advertising are contributing to an increase in social welfare compared to situations without advertising. ${ }^{10}$

Another relevant literature for our analysis is theories on quality disclosure (third-party disclosure and self-disclosure). The literature on third party disclosure is mainly concerned with the supply side of the market, focusing on issues such as the choice of disclosure rules, incentives for truthful reporting among accreditation bodies (certifiers), optimal audit fees, and the role of competition (Albano and Lizzeri, 2001; Hvide and Heifetz, 2001; Lizzeri, 1999; Miao, 2009). The so-called "unravelling literature", being an important part of the literature on self-disclosure, is typically concerned with disclosure incentives where disclosure reveals the exact product quality and where the firms are local monopolies (strategic independence) since fully capturing the consumer surplus. ${ }^{11}$ The role of competition (oligopolistic markets) is addressed by Stivers (2004), Cheong and Kim (2004), Board (2009), Levin et al. (2009) and Guo and Zhao (2009), Caldieraro et al. (2011), Hotz and Xiao (2013) and Janssen and Roy (2015). All these studies analyse price competition for substitutes where disclosure reveals information on exact product quality and where the disclosure costs are exogenous. The same studies vary in regard to assumptions about product differentiation (horizontal and/or vertical), consumer information and consumer preferences, the firms' information about rivals, and how competition is portrayed. Most works find that greater competition decreases disclosure. ${ }^{12}$

The structure of the paper is as follows. In Section 2, we present the basic model. In Section 3, we deduce the optimal cartel solution. In Section 4, we consider competitive games, where the firms either compete in quantities or prices. In both cases we study when the accreditation decisions are taken simultaneously with the choices on quantities or prices, and when the accreditation decisions are made before the firms to compete in quantities or prices. In Section 5, we compare the different markets structures with respect to accreditation incentives and analyse the impact from increased

\footnotetext{
${ }^{10}$ The main discussions in these referred articles are related to whether advertising in oligopolies is welfare improving or not, and eventually different political means that could be practiced in order to promote overall market efficiency.

${ }^{11}$ The term "unraveling" refers to the process whereby the firm with the highest product quality is first to disclose as a way of distinguishing itself from lower quality firms. Once this happens, the firm with the second highest product quality has the same incentive to disclose, and so forth until all but the firm with lowest quality discloses. This literature derives from early works by Grossman and Hart (1980) and Milgrom (1981) showing, in the absence of disclosure costs, that all firms disclose their true type (full disclosure). Subsequent works have identified conditions for partial disclosure. Viscusi (1978), Jovanovic (1982), Grossmann and Hart (1980), and Dye and Sridhar (1995) show that disclosure costs may yield partial disclosure. 12 Two exceptions are Stivers (2004) and Caldieraro et al. (2011).
} 
competition. In Section 6, we present optimal welfare solutions. Section 7 discusses some model extensions while section 8 concludes.

\section{The model}

Consider a market with only one accreditation body (certifier). ${ }^{13}$ Accreditation is assumed to be an endogenous discrete (binary) decision variable for the firms. This means that either a firm chooses to accredit or it decides not to become accredited. ${ }^{14}$ Here we symbolize the action of accreditation for firm $i$ by $A_{i}=1$ if it is accredited, and $A_{i}=0$ if the firm decides not to become accredited.

Let there be two profit-seeking firms, firm $i$ and $j$, producing and selling differentiated products in two markets ( $i$ and $j)$, which might be interrelated either as substitutes or complements in demand. Moreover, we suppose that demand in market $i$ depends on the price in this market, $p_{i}$, the price in the other market $j, p_{j}$, whether the producer in each market is accredited, $A_{i}=1$ and $A_{i}=0$ and $A_{j}=1$ and $A_{j}=0$. This means that we can specify the demand function as $q_{i}=q_{i}\left(p_{i}, p_{j}, A_{i}, A_{j}\right)$, where $\frac{\partial q_{i}}{\partial p_{i}}<0, \frac{\partial q_{i}}{\partial A_{i}}>0$ and $\frac{\partial q_{i}}{\partial p_{j}}>(\leq) 0, \frac{\partial q_{i}}{\partial A_{j}}<(\geq) 0$ if the products are substitutes (complements). This implies that higher prices reduce demand, firm accreditation increases own market demand, and lower prices and accreditation in the other market increase (decrease) demand in the case of substitutes (complements). We propose a model similar to the linear specification of Singh and Vives (1984) with an expansion regarding the accreditation elements, $A_{i}$. Given these assumptions, the inverse demand firm $i$ is facing becomes as follows:

$$
\begin{aligned}
& p_{i}=a_{i}-q_{i}-g q_{j}+\gamma_{i} A_{i}-g \lambda_{i} A_{j} \\
& \text { where } i, j=\{1,2\}, i \neq j, a_{i}, q_{i}, \gamma_{i}, \lambda_{i}>0, \gamma_{i}>\lambda_{i},-1<g<1 \text { and } A_{i}=0 \text { or } A_{i}=1
\end{aligned}
$$

In (1a), the symmetric parameter $g$ indicates how differentiated the products are for the two firms. The firms provide independent products if $g=0$ and the products become closer to perfect substitutes (complements) as $g \rightarrow 1$ ( $g \rightarrow-1$ ). Hence, the value of $g$ indicates the degree of product differentiation while $\lambda_{i}$ determines, for a given degree of product differentiation, how the willingness

\footnotetext{
${ }^{13}$ Here we assume a fixed accreditation fee (e.g. a single regulated accreditation body).

${ }^{14}$ According to a UNESCO publication the result of an accreditation process is the awarding of a status (yes/no decision) (Vlãsceanu, Grünberg, and Parlea, 2004). According to Van Damme (2004) it is important to narrow the use of the term, accreditation, and to separate it conceptually from other quality assurance activities. Conditions that have to be fulfilled in order to use the term consistently are; (i) a formal decision of binary (yes/no) or ternary (adding "conditional") nature and (ii) based upon predetermined standards or requirements (benchmarks). This means that accreditation best can be perceived as a strategic discrete variable (comparable to models on exit and entry decisions), making it different from models on quality competition and advertisement where firms are supposed to adjust their strategic means continuously when they maximize profits.
} 
to pay for product $i$ is affected by the accreditation decision of the rival. It follows from (1a) that a firm that decides to become accredited will experience a positive shift in the marginal willingness to pay for its product, while the other firm, operating in a substitutable (complementary) market, will experience a negative (positive) shift in the marginal willingness to pay for its product. These effects follow from the consumers' beliefs that successful accreditation by an operator in a market is a signal of better product quality, which is adding value to the product provided by this firm. At the same time, when a producer chooses to provide an accredited good in its market, the other firm will experience lower willingness to pay for its product if the goods are substitutable in consumption, and higher willingness to pay if the goods are complementary in consumption. It seems reasonable to assume that the direct effect of becoming accredited is stronger than the effect of possible accreditation in the other market, which implies that $\gamma_{i}>g \lambda_{i}$. Our formulation of the effects on the marginal willingness to pay for accreditation is simple but captures potentially important effects. First, becoming accredited, ceteris paribus, improves your relative position in the market relative to non-accredited rivals, and second, it may cause an increase in the overall demand (market expansion effect). Given the demand functions in (1a), it follows that the quantity specifications become:

$$
q_{i}=\frac{1}{1-g^{2}}\left[a_{i}-g a_{j}+\left(\gamma_{i}+g^{2} \lambda_{j}\right) A_{i}-g\left(\gamma_{j}+\lambda_{i}\right) A_{j}-p_{i}+g p_{j}\right]
$$

The technology of firm $i$, is given by the cost functions $C_{i}$ :

$$
C_{i}=C_{i}\left(q_{i}, A_{i}\right)=\left(c_{i}+l_{i} A_{i}\right) q_{i} \text { where } c_{i}>\left|l_{i}\right|
$$

We assume that $\frac{\partial C_{i}}{\partial q_{i}}=c_{i}+l_{i} A_{i}$ and $\frac{\partial C_{i}}{\partial A_{i}}=l_{i} q_{i}$. This means that there is a constant marginal cost in production, only affected by accreditation or not. $c_{i}$ represents the unit production cost in the absence of accreditation while $l_{i}$ represents the change in such costs from becoming accredited. The condition $c_{i}>\left|l_{i}\right|$ ensures that production unit costs are positive also after becoming accredited. The parameter $l_{i}$ is designed to reflect all changes in costs that occur in response to meeting accreditation standards and may include audit fees, outside consulting costs, and initial internal costs such as documentation costs and staff-training costs. In addition, there are costs associated with changing production processes (compliance costs), which in principle can be both positive (efforts to fulfil input standards) or negative (cost-efficiency gains that arise from learning). Let $l_{i}$ now be the sum of all cost additions, $\tau_{i}$, and all cost savings, $\rho_{i}$, that follow from becoming accredited, which yields; $l_{i}=\left(\tau_{i}-\rho_{i}\right)$. If $\tau_{i}<\rho_{i}$, the change in unit production costs associated with becoming accredited is negative.

The profit function for firm $i, \pi_{i}$, can then, using (1a) and (2), be written as 


$$
\pi_{i}=\left(a_{i}-c_{i}+A_{i}\left(\gamma_{i}-l_{i}\right)-g \lambda_{i} A_{j}-q_{i}-g q_{j}\right) q_{i}
$$

or alternatively, using (2) and the direct demand functions (1b), by

$$
\pi_{i}=\frac{1}{1-g^{2}}\left[a_{i}-g a_{j}+\left(\gamma_{i}+g^{2} \lambda_{j}\right) A_{i}-g\left(\gamma_{j}+\lambda_{i}\right) A_{j}-p_{i}+g p_{j}\right]\left(p_{i}-c_{i}-l_{i} A_{i}\right)
$$

As expected, we observe from (3a) and (3b) that profit for firm $i$ is a function of both own and the rival's accreditation decision. For the market to exist, $q_{i}>0$, it is required that the profit for the first unit must be strictly positive for both players, i.e.,

$$
\omega_{i}=a_{i}-c_{i}+A_{i}\left(\gamma_{i}-l_{i}\right)-g \lambda_{i} A_{j}=\omega_{i}\left(A_{i}, A_{j}\right)>0
$$

By inserting (4) into (3a), profits can be expressed as follows;

$$
\pi_{i}=\left(\omega_{i}\left(A_{i}, A_{j}\right)-q_{i}-g q_{j}\right) q_{i} \text { where } i, j=1,2 \text { and } i \neq j
$$

The value of $\omega_{i}$ measures the difference between the marginal willingness to pay for the first unit of product $i$ subtracted the cost of producing the same unit (marginal welfare surplus). We observe that $\omega_{i}$ is negatively (positively) affected when firm $j$ becomes accredited if the goods are substitutes (complements) in consumption (hence $-g \lambda_{i}<(>) 0$ ) and that $\omega_{i}$ is positively (negatively) affected when firm $i$ becomes accredited if $\gamma_{i}-l_{i}>(<) 0$.

The changes in profit for firm $i$, for a given quantity level, that occur in response to choosing own accreditation and the rival choosing accreditation become:

(6a) $\frac{\partial \pi_{i}}{\partial A_{i}}=\frac{\partial \omega_{i}\left(A_{i}, A_{j}\right)}{\partial A_{i}} q_{i}=\left(\gamma_{i}-l_{i}\right) q_{i}$

(6b) $\quad \frac{\partial \pi_{i}}{\partial A_{j}}=\frac{\partial \omega_{i}\left(A_{i}, A_{j}\right)}{\partial A_{j}} q_{i}=-g \lambda_{i} q_{i}$

The effect in (6a) represents a direct effect since it refers to profit changes following from own decision of becoming accredited. ${ }^{15}$ This effect depends on the sum of the marginal increase in the willingness to pay for own product if being accredited and the accompanying change in marginal costs (direct net benefit from accreditation), and can be both positive or negative depending on $\gamma_{i}-$ $l_{i}=\gamma_{i}-\left(\tau_{i}-\rho_{i}\right)>(<) 0$. The effect in $(6 \mathrm{~b})$ is an indirect effect since referring to profit changes arising from the rival's accreditation decision. This effect depends on the degree (and type) of product differentiation, $g$, and on how the willingness to pay for product $i$ is affected by the accreditation decision of the rival, $\lambda_{i}$. This indirect effect can be both positive or negative since

\footnotetext{
${ }^{15}$ In view of the discrete nature of the accreditation variable, the equations (6a) and (6b) should be expressed as; $\pi_{i}\left(A_{i}=1 ; A_{j}\right)-\pi_{i}\left(A_{i}=0, A_{j}\right)=\left(\gamma_{i}-l_{i}\right) q_{i}$ and $\pi_{i}\left(A_{i} ; A j=1\right)-\pi_{i}\left(A_{i}, A_{j}=0\right)=-g \lambda_{i} q_{i}$ where $i, j=1,2, i \neq j$.
} 
depending on markets being substitutes or complements $\left(g \lambda_{i}>(<) 0\right)$.

\section{Cooperative behaviour (cartel)}

Here, we identify the optimal conditions given cooperative behaviour in order to study a cartel's $(K)$ incentives to accredit. When supposing that the firms cooperate and decide to maximize the sum of the profits defined by (5), it is found that the first order conditions make it possible to specify the optimal cartel behaviour as follows:

(7a)

$$
q_{i}^{K}=\frac{\omega_{i}\left(A_{i}^{K}, A_{j}^{K}\right)-g \omega_{j}\left(A_{i}^{K}, A_{j}^{K}\right)}{2\left(1-g^{2}\right)}
$$

$$
p_{i}^{K}=c_{i}+l_{i} A_{i}^{K}+\frac{\omega_{i}\left(A_{i}^{K}, A_{j}^{K}\right)}{2}
$$

$$
\pi_{i}^{K}=\frac{\left[\omega_{i}\left(A_{i}^{K}, A_{j}^{K}\right)-g \omega_{j}\left(A_{i}^{K}, A_{j}^{K}\right)\right] \omega_{i}\left(A_{i}^{K}, A_{j}^{K}\right)}{4\left(1-g^{2}\right)}
$$

$$
A_{i}^{K}=1 \text { if }\left(\gamma_{i}-l_{i}\right) q_{i}^{K}-g \lambda_{j} q_{j}^{K}>0 \text { or } A_{i}^{K}=0 \text { if }\left(\gamma_{i}-l_{i}\right) q_{i}^{K}-g \lambda_{j} q_{j}^{K} \leq 0
$$

Equations (7a)-(7d) represent the cartel equilibrium for quantities, prices and profits, where the optimal decisions reflect coordinating behaviour leading to monopoly power. ${ }^{16}$ The conditions in (7d) define the optimal accreditation decision and depend on the relative significance of two effects. The first effect is the direct effect, already described in (6a), while the second effect, measured by $g \lambda_{j}$, reflects how an accreditation in market $i$ affects the marginal willingness to pay in market $j$, which again depends on the products being substitutes or complements. The effect in (6b), being a function of $\lambda_{i}$, describes the effect on own profit (willingness to pay for own product) from the rival seeking accreditation, while the effect in (7d), since being a function of $\lambda_{j}$, refers to the effect firm $i^{\prime}$ s accreditation decision has on the rivals' profit. ${ }^{17}$ Hence, the effect in (7d) reflects the cartel's ability to coordinate the firms' behaviour, meaning that the mutual effects in the two markets are fully internalized when each firm makes their accreditation decision. This is seen by considering independent markets $(g=0)$. Now this effect (see $(7 d))$ plays no role on the accreditation decision.

Given products being substitutes $(0<g<1)$ the indirect effect is negative while for products being complements $(-1<g<0)$ the same effect is positive. Thus, the incentive for a cartel firm to seek

\footnotetext{
${ }^{16}$ It follows from (7a) that a positive equilibrium quantity in both markets implies that $\omega_{i}\left(A_{i}^{K}, A_{j}^{K}\right)-g \omega_{j}\left(A_{i}^{K}, A_{j}^{K}\right)>0$ where $i, j=1,2, i \neq j$. Here and throughout the analyses we do not specify the second order conditions for the different market solutions, but assume that they are satisfied.

${ }^{17}$ The indirect effect in (7d) relates to the following change in profit; $\pi_{j}\left(A_{i}=1 ; A_{j}\right)-\pi_{j}\left(A_{i}=0, A_{j}\right)=-g \lambda_{j} q_{j}$ where $i, j=1,2, i \neq j$.
} 
accreditation, ceteris paribus, is stronger in markets for complements relative to markets for substitutes. We also observe from (7d) that for markets being complements, cartel firms will always seek accreditation if the direct effect (direct net benefit from accreditation) is positive. For markets being substitutes, cartel firms will never seek accreditation if the same effect is negative. It also follows that a cartel firm may find it advantageous to accredit also when accreditation does not increase the willingness to pay for own products $\left(\gamma_{i}=0\right)$. This may occur if the change in accreditation costs is negative; $l_{i}=\left(\tau_{i}-\rho_{i}\right)$ where $\tau_{i}<\rho_{i}$.

\section{Non-cooperative games}

In this section, we analyse the situation where two firms independently make their accreditation and price/quantity decisions. Competition on quantity (Cournot) and price (Bertrand) are denoted C and $B$, respectively. In many situations, it seems reasonable to portray firms as making their accreditation decision in advance of the more flexible competition in quantities or prices. Consequently, first, we derive equilibria for the cases where the firms simultaneously make their quantity- and accreditation decisions (simultaneous Cournot indicated by notation SC). Secondly, we analyse the case where accreditation choices are made and observed before the firms decide on their quantity levels (twostage Cournot indicated by NC). Thirdly, we derive equilibria for the cases where the firms simultaneously make their accreditation - and price decisions (simultaneous Bertrand indicated by SB). Finally, we study the case where the firms first make their accreditation choices followed by a price competition (two-stage Bertrand indicated by NB).

\subsection{The Cournot games}

We first consider firms that simultaneously make accreditation choices and quantity choices (simultaneous Cournot). By maximizing the profits given by (5) with regard to quantities and the accreditation decision, and manipulating the first order conditions we find that the equilibrium can be defined by:

(8a) $\quad q_{i}^{C}=\frac{2 \omega_{i}\left(A_{i}^{C}, A_{j}^{C}\right)-g \omega_{j}\left(A_{i}^{C}, A_{j}^{C}\right)}{4-g^{2}}$

(8b) $\quad p_{i}^{C}=c_{i}+l_{i} A_{i}^{C}+\frac{2 \omega_{i}\left(A_{i}^{C}, A_{j}^{C}\right)-g \omega_{j}\left(A_{i}^{C}, A_{j}^{C}\right)}{4-g^{2}}$

(8c) $\quad \pi_{i}^{C}=\frac{\left[2 \omega_{i}\left(A_{i}^{C}, A_{j}^{C}\right)-g \omega_{j}\left(A_{i}^{C}, A_{j}^{C}\right)\right]^{2}}{\left(4-g^{2}\right)^{2}}$ 


$$
A_{i}^{C}=A_{i}^{S C}=1 \text { if }\left(\gamma_{i}-l_{i}\right) q_{i}^{C}>0 \text { or } A_{i}^{C}=A_{i}^{S C}=0 \text { if }\left(\gamma_{i}-l_{i}\right) q_{i}^{C} \leq 0
$$

where $A_{i}^{S C}$ symbolize the optimal accreditation decision given simultaneous Cournot. The exact quantities, $q_{i}^{S C}$, prices, $p_{i}^{S C}$, and profits, $\pi_{i}^{S C}$, in (8a)-(8c) are calculated by using the optimal values of $A_{i}^{S C}$ in (8d). If we compare (8a)-(8d) with the cartel solution for independent markets $(g=0)$, it is evident that equilibrium quantities, prices, profits and accreditation choices coincide. Moreover, the interpretation of the Cournot equilibrium in prices and quantities (8a)-(8c) is identical to Singh and Vives (1984). Additionally, it follows from (8d) that whether a firm will seek accreditation is dependent on the sign of $\gamma_{i}-l_{i}$. The firm seeks accreditation if the increase in the marginal willingness to pay in the market where it operates, $\gamma_{i}$, is higher than the marginal increase in firm costs, $l_{i}$. If the opposite holds, then accreditation does not increase the profit, and the firm chooses not to accredit. It should be remarked that for this simultaneous Cournot competition, unlike the case of cartel firms, that only the direct demand effect plays a role when evaluating the gains and losses regarding accreditation.

In order to solve the two-step Cournot game, we use backward induction. In stage 2, the firms maximize profits given by (5) with regard to quantities, for a given accreditation decision, and again we obtain the equations (8a)-(8c) for the quantities, prices and profits. The only difference is that the accreditation choice for the firms in the two-stage Cournot, symbolized by $A_{i}^{N C}$, is found by maximizing (8c) with regard to $A_{i}$. The optimality is secured if the following conditions are satisfied:

$A_{i}^{C}=A_{i}^{N C}=1$ if $\frac{\partial \pi_{i}^{C}}{\partial A_{i}}=\frac{2\left(2 \omega_{i}\left(A_{i}^{C}, A_{j}^{C}\right)-g \omega_{j}\left(A_{i}^{C}, A_{j}^{C}\right)\right)\left[2\left(\gamma_{i}-l_{i}\right)+g^{2} \lambda_{j}\right]}{\left(4-g^{2}\right)^{2}}>0$ or $A_{i}^{C}=A_{i}^{N C}=0$ if $\frac{\partial \pi_{i}^{C}}{\partial A_{i}}=\frac{2\left(2 \omega_{i}\left(A_{i}^{C}, A_{j}^{C}\right)-g \omega_{j}\left(A_{i}^{C}, A_{j}^{C}\right)\right)\left[2\left(\gamma_{i}-l_{i}\right)+g^{2} \lambda_{j}\right]}{\left(4-g^{2}\right)^{2}} \leq 0$, which again implies

$$
A_{i}^{N C}=1 \text { if } 2\left(\gamma_{i}-l_{i}\right)+g^{2} \lambda_{j}>0 \text { or } A_{i}^{N C}=0 \text { if } 2\left(\gamma_{i}-l_{i}\right)+g^{2} \lambda_{j} \leq 0
$$

Using (8e) in (8a)-(8c) gives the optimal values of quantities, prices and profits in this case. From (8e) it follows, as was the case for the cartel, that the optimal accreditation decision depends both on a direct and an indirect effect. However, the indirect effect plays no role for the accreditation decision when products are independent $(g=0)$. We also observe that the indirect effect in $(8 \mathrm{e})$, as was the case for cartel firms, is a function of $\lambda_{j}$ (and not $\lambda_{i}$ ), pointing to concerns for how the willingness to pay for the product of the rival firm (firm $j$ ) is affected by own accreditation decision. This means, for a given degree of product differentiation, that the accreditation incentive of firm $i$ rises with the size of the effect that own accreditation has on the willingness to pay for the rivals' product. In difference from simultaneous Cournot (see $8 \mathrm{~d}$ ), this indirect effect occurs because of the sequential nature of 
this game that again ensures a partial internalization of the effects that run via the rival's market. Each firm takes into account the rivals' reaction at stage two when considering whether to seek accreditation or not. It also follows from (8e) that each firm has dominating strategies since the optimal accreditation decision is independent of the rivals' accreditation decision (independent of $g \lambda_{i}$ and $\left.q_{j}\right)$.

A new finding, relative to cartel firms, is that the indirect effect in (8e) is strictly positive both for substitutes and complements, which makes the sign of this effect, given substitutes $(0<g<1)$, opposite of the indirect effect for cartel firms. This finding is a result of the product of two negative effects. First, it is seen from (4) and (8a) that accreditation in market $i$ leads to a reduced marginal willingness to pay in the other market, which again causes a reduction in the two-stage Cournot quantity in the same market - the firm operating in market $j$ has an incentive to reduce the quantity supplied at stage two. Second, from (5), the profit in market $i$ will increase as the supply in market $j$ is reduced. Altogether this means that choosing accreditation in market $i$ leads to a positive indirect effect on firm $i$ 's profit. In contrast to the cartel, the absence of coordination in two-stage Cournot markets makes the possibility to accredit a mutual threat that again reinforces the incentives for seeking accreditation. Since the indirect effect is positive, this implies that a firm in the case of a twostage Cournot might find it beneficial to accredit in cases where the direct effect is negative; $\gamma_{i}-$ $l_{i}<0$. This will happen if the direct effect is dominated by the indirect effect (hence $2\left(\gamma_{i}-l_{i}\right)>$ $-g^{2} \lambda_{j}$ ).

Given complements, the mechanisms behind the positive indirect effect are now different since they are the product of two positive effects. First, accreditation in market $i$ leads to an increase in the willingness to pay in market $j$, which again causes an increase in the two-stage Cournot quantity in this market - the firm operating in market $j$ has an incentive to increase the quantity supplied at stage two. Second, from (5), the profit in market $i$ will increase as the supply in market $j$ is increased. Altogether, this means that choosing accreditation in market $i$ leads to a positive indirect effect on firm $i$ 's profit. It should also be noticed by comparing (8d) and (8e) that the direct effect is multiplied by 2 in the two-stage Cournot game compared to the simultaneous Cournot case.

\subsection{The Bertrand games}

First, consider firms that simultaneously choose both prices and whether to accredit or not at the same time (simultaneous Bertrand). By maximizing the profit function in (3b) with regard to price and the accreditation decision, and manipulating the expressions using the definitions in (4), we obtain the following conditions for equilibrium in simultaneous Bertrand competition: 
(9a) $\quad q_{i}^{B}=\frac{\left(2-g^{2}\right) \omega_{i}\left(A_{i}^{B}, A_{j}^{B}\right)-g \omega_{j}\left(A_{i}^{B}, A_{j}^{B}\right)}{\left(1-g^{2}\right)\left(4-g^{2}\right)}$

(9b) $\quad p_{i}^{B}=c_{i}+l_{i} A_{i}^{B}+\frac{\left(2-g^{2}\right) \omega_{i}\left(A_{i}^{B}, A_{j}^{B}\right)-g \omega_{j}\left(A_{i}^{B}, A_{j}^{B}\right)}{4-g^{2}}$

(9c) $\quad \pi_{i}^{B}=\frac{\left[\left(2-g^{2}\right) \omega_{i}\left(A_{i}^{B}, A_{j}^{B}\right)-g \omega_{j}\left(A_{i}^{B}, A_{j}^{B}\right)\right]^{2}}{\left(1-g^{2}\right)\left(4-g^{2}\right)^{2}}$

(9d) $\quad A_{i}^{B}=A_{i}^{S B}=1$ if $\left[\gamma_{i}-l_{i}+\lambda_{j} g^{2}\right] q_{i}^{B}>0$ or $A_{i}^{B}=A_{i}^{S B}=0$ if $\left[\gamma_{i}-l_{i}+\lambda_{j} g^{2}\right] q_{i}^{B} \leq 0$

where $A_{i}^{S B}$ symbolizes the optimal accreditation decision for simultaneous Bertrand. The exact values of quantities, prices and profits are found by using (9d) in (9a)-(9c). Simultaneous Bertrand competition produces the standard equilibrium prices and quantities identified by Singh and Vives (1984), and, if the accreditation decisions are taken simultaneously with the choices of prices, it follows from (9d) that the accreditation decisions are dependent on the sign on $\gamma_{i}-l_{i}+\lambda_{j} g^{2}$. If this expression is positive, accreditation by firm $i$ will cause an increase in demand for firm $i$ that outweighs the possible cost increase from accreditation. If this expression is zero or negative, the firm has no incentive to accredit. Like the case for cartel firms and two-stage Cournot competition, the optimal accreditation decision depends on both a direct and an indirect effect on demand. As for the case of two-stage Cournot, the sign of the indirect effect is positive for both substitutes and complements due to the same reasons as mentioned above.

The two-step Bertrand game is solved by backward induction. In stage 2, the firms maximize profits for a given accreditation decision, which yields the same equalities as (9a)-(9c). The optimal accreditation decision of firm $i$ at stage 1 follows from maximizing the profit of firm $i$, defined by (9c), with regard to $A_{i}$. Hence, the optimal accreditation decision in this non-simultaneous case, symbolized by $A_{i}^{N B}$, must satisfy the following conditions:

$A_{i}^{B}=A_{i}^{N B}=1$ if $\frac{\partial \pi_{i}^{B}}{\partial A_{i}}=\frac{\left.2\left[\left(2-g^{2}\right) \omega_{i}\left(A_{i}^{B}, A_{j}^{B}\right)-g \omega_{j}\left(A_{i}^{B}, A_{j}^{B}\right)\right)\right]\left[\left(2-g^{2}\right)\left(\gamma_{i}-l_{i}\right)+g^{2} \lambda_{j}\right]}{\left(4-g^{2}\right)^{2}}>0$

$A_{i}^{B}=A_{i}^{N B}=0$ if $\frac{\partial \pi_{i}^{B}}{\partial A_{i}}=\frac{2\left[\left(2-g^{2}\right) \omega_{i}\left(A_{i}^{B}, A_{j}^{B}\right)-g \omega_{j}\left(A_{i}^{B}, A_{j}^{B}\right)\right]\left[\left(2-g^{2}\right)\left(\gamma_{i}-l_{i}\right)+g^{2} \lambda_{j}\right]}{\left(4-g^{2}\right)^{2}} \leq 0$

which again produces the following conditions;

$$
A_{i}^{N B}=1 \text { if }\left(2-g^{2}\right)\left(\gamma_{i}-l_{i}\right)+g^{2} \lambda_{j}>0 \text { or } A_{i}^{N B}=0 \text { if }\left(2-g^{2}\right)\left(\gamma_{i}-l_{i}\right)+g^{2} \lambda_{j} \leq 0
$$

Using (9e) in (9a)-(9c) gives the optimal values of quantities, prices and profits in this case. As in the case for the cartel, simultaneous Bertrand and two-stage Cournot, the optimal accreditation decision under two-stage Bertrand depends on a direct effect and an indirect effect given non-independent 
products $(g \neq 0)$. As in the Cournot cases, we observe that; (i) the indirect effect depends on how the willingness to pay for the product of the rival firm (firm $j$ ) is affected by own accreditation decision, $\lambda_{j}$, and, (ii) the indirect effect is positive both when products are substitutes and complements.

The indirect effect follows from the sequential nature of the game. Each firm takes into account the rivals' reaction at stage two when evaluating the accreditation alternative. Given substitutes, the corresponding reduction in the marginal willingness to pay in the other market induces the firm operating there to reduce the price at stage two. Again, the absence of coordination implies that the accreditation decision represents a mutual threat that reinforces the incentive for seeking accreditation. The negative indirect effect for substitutes implies that in the two-stage Bertrand game, a firm will find it advantageous to accredit also in cases where the direct effect is negative, i.e. $\gamma_{i}-l_{i}<0$. It should also be remarked that for any $g$ different from zero, the direct effect is less than twice of the effect in simultaneous Cournot, i.e. lower than in the two-stage Cournot, but higher than in simultaneous Cournot.

Given complements, accreditation in one market leads to an increase in the willingness to pay in the other market, which again leads to a higher price in this market and a positive shift in the marginal willingness to pay in the first market. Again, Bertrand firms might seek accreditation also when the direct effect is negative. However, the accreditation incentives are now weaker compared with cartel firms since Bertrand firms do not fully internalize all mutual market effects.

\section{Comparing accreditation incentives across market structures}

From sections 3 and 4 it follows that each firm, independent of market structure and degree of product differentiation, has dominating strategies. Furthermore, depending on the relative relationships between demand-and cost conditions (based on differences in the size of the parameters $a_{i}, c_{i}, \gamma_{i}, l_{i}$ and $\left.\lambda_{i}\right)$, all types of equilibria may occur; thus, we have situations where both firms choose to accredit, where both firm choose to stay non-accredited, and situations where one firm may find it advantageous to seek accreditation while the rival does not. However, the incidence of the various types, for similar parameter values, is expected to vary across markets. 
In this section, we discuss the differences in firms' incentives to accredit across the various market structures. ${ }^{18}$ We first consider products that are substitutes for then to consider products that are complements. Given products that are substitutes $(0<g<1)$ it follows from (7d), (8d), (8e), (9d) and $(9 e)$ that we can consider different intervals of the factor $\frac{\gamma_{i}-l_{i}}{\lambda_{j}}$ that again produce different incentives for seeking accreditation. It can be shown that

$$
\frac{\gamma_{i}-l_{i}}{\lambda_{j}} \leq-g^{2} \quad \Rightarrow \quad A_{i}^{S B}=A_{i}^{N B}=A_{i}^{N C}=A_{i}^{S C}=A_{i}^{K}=0
$$

$$
-g^{2}<\frac{\gamma_{i}-l_{i}}{\lambda_{j}} \leq-\frac{g^{2}}{2-g^{2}} \Rightarrow A_{i}^{S B}=1, A_{i}^{N B}=A_{i}^{N C}=A_{i}^{S C}=A_{i}^{K}=0
$$

$$
-\frac{g^{2}}{2-g^{2}}<\frac{\gamma_{i}-l_{i}}{\lambda_{j}} \leq-\frac{g^{2}}{2} \Rightarrow A_{i}^{S B}=A_{i}^{N B}=1, A_{i}^{N C}=A_{i}^{S C}=A_{i}^{K}=0
$$

$$
-\frac{g^{2}}{2}<\frac{\gamma_{i}-l_{i}}{\lambda_{j}} \leq 0 \quad \Rightarrow A_{i}^{S B}=A_{i}^{N B}=A_{i}^{N C}=1, A_{i}^{S C}=A_{i}^{K}=0
$$

$$
0<\frac{\gamma_{i}-l_{i}}{\lambda_{j}} \leq g \frac{q_{j}^{K}}{q_{i}^{K}} \quad \Rightarrow \quad A_{i}^{S B}=A_{i}^{N B}=A_{i}^{N C}=A_{i}^{S C}=1, A_{i}^{K}=0
$$

$$
\frac{\gamma_{i}-l_{i}}{\lambda_{j}}>g \frac{q_{j}^{K}}{q_{i}^{K}} \quad \Rightarrow \quad A_{i}^{S B}=A_{i}^{N B}=A_{i}^{N C}=A_{i}^{S C}=A_{i}^{K}=1
$$

It follows from (s1) through (s6) that the accreditation incentives vary across the five competitive market structures for similar parameter values. Figure 1 sums up the findings where each arrow identifies the interval for when a firm will choose accreditation for a particular market structure (cartel, simultaneous and two-stage Cournot and simultaneous and two stage Bertrand). Since the degree of competition can be said to increase when moving from a cartel, to a simultaneous Cournot, to a two-stage Cournot, to a two-stage Bertrand, and, finally to a simultaneous Bertrand game, it follows that the incentives for seeking accreditation are increasing with the degree of market competition. Additionally, for substitutable goods $(0<g<1)$, the degree of product differentiation also reflects the degree of competition, and it is straightforward to show that the higher the degree of competition, interpreted as $g$ approaching 1 , a higher value for $\frac{\gamma_{i}-l_{i}}{\lambda_{j}}$ is needed for the cartel to seek accreditation, i.e. the cartel's incentive for accreditation is weakened as $g$ grows. In the simultaneous Cournot, the incentive to accredit is independent of the value of $g$, while in two-stage

\footnotetext{
${ }^{18}$ Here we focus on firm's incentives to seek accreditation. Firm $j$ has similar incentives, but as the demand and cost parameters may vary across markets, one might find that the firms choose different strategies regarding accreditation, i.e. separating equilibria might occur. If the parameters are identical, we have a symmetric case where both either choose to accredit or not, i.e. one of the possible two pooling equilibria.
} 
Cournot, two-stage Bertrand and simultaneous Bertrand, the incentive to seek accreditation is increased when $g$ becomes higher. ${ }^{19}$

Insert Figure 1 about here.

Given products that are complements $(-1<g<0)$, we can consider different intervals of the factor $\frac{\gamma_{i}-l_{i}}{\lambda_{j}}$ that produce different accreditation incentives. It can be shown that;

(c1)

$$
\frac{\gamma_{i}-l_{i}}{\lambda_{j}} \leq g \frac{q_{j}^{K}}{q_{i}^{K}} \quad \Rightarrow \quad A_{i}^{K}=A_{i}^{S B}=A_{i}^{N B}=A_{i}^{N C}=A_{i}^{S C}=0
$$

$$
g \frac{q_{j}^{K}}{q_{i}^{K}}<\frac{\gamma_{i}-l_{i}}{\lambda_{j}} \leq-g^{2} \quad \Rightarrow \quad A_{i}^{K}=1, A_{i}^{S B}=A_{i}^{N B}=A_{i}^{N C}=A_{i}^{S C}=0
$$

$$
-g^{2}<\frac{\gamma_{i}-l_{i}}{\lambda_{j}} \leq-\frac{g^{2}}{2-g^{2}} \Rightarrow A_{i}^{K}=A_{i}^{S B}=1, A_{i}^{N B}=A_{i}^{N C}=A_{i}^{S C}=0
$$

$$
-\frac{g^{2}}{2-g^{2}}<\frac{\gamma_{i}-l_{i}}{\lambda_{j}} \leq-\frac{g^{2}}{2} \Rightarrow A_{i}^{K}=A_{i}^{S B}=A_{i}^{N B}=1, A_{i}^{N C}=A_{i}^{S C}=0
$$

$$
-\frac{g^{2}}{2}<\frac{\gamma_{i}-l_{i}}{\lambda_{j}} \leq 0 \quad \Rightarrow \quad A_{i}^{K}=A_{i}^{S B}=A_{i}^{N B}=A_{i}^{N C}=1, A_{i}^{S C}=0
$$

(c6) $\quad \frac{\gamma_{i}-l_{i}}{\lambda_{j}}>0$

$$
\Rightarrow \quad A_{i}^{K}=A_{i}^{S B}=A_{i}^{N B}=A_{i}^{N C}=A_{i}^{S C}=1
$$

Figure 2 illustrates how accreditation incentives, defined by (c1) through (c6), vary across the five types of market competition. We observe that the relative relationships between the five markets differ from our findings for substitutable products. Now, the incentives for seeking accreditation are highest for cartel firms, followed by simultaneous Bertrand firms, two-stage Bertrand firms, twostage Cournot firms, while being weakest for simultaneous Cournot firms. The size of $g$ for complements can be interpreted as the degree of coordination, where $g$ approaching -1 is reflecting a higher degree of coordination. It is straightforward to show that as $g$ approaches - 1 , the higher the incentives for seeking accreditation in all cases expect for the simultaneous Cournot case where the incentive is independent of the value of $g .{ }^{20}$

${ }^{19}$ Let $u \equiv-g^{2}, v \equiv \frac{-g^{2}}{2}$ and $w \equiv \frac{-g^{2}}{2-g^{2}}$, then $\frac{d u}{d g}=-2 g<0, \frac{d v}{d g}=-g<0$ and $\frac{d w}{d g}=\frac{-4 g}{\left(2-g^{2}\right)^{2}}<0$ as $g>0$, meaning that the limits for seeking accreditation in two-stage Cournot and the two Bertrand games move leftwards in Figure 1 as $g$ becomes closer to 1 .

${ }^{20}$ Using the same notation as in footnote 19, now $\frac{d u}{d g}=-2 g>0, \frac{d v}{d g}=-g>0$ and $\frac{d w}{d g}=\frac{-4 g}{\left(2-g^{2}\right)^{2}}>0$ as $g<0$. This means that the limits in the two-stage Cournot and Bertrand games for seeking accreditation move leftwards in Figure 2 as $g$ reduces and becomes closer to -1; see also footnote 19 . 
Insert Figure 2 about here.

If we now compare the two Cournot solutions (SC and NC) in the interval when $-\frac{g^{2}}{2}<\frac{\gamma_{i}-l_{i}}{\lambda_{j}} \leq 0$, it follows that $A_{i}^{N C}=1$ and $A_{i}^{S C}=0$. Suppose now that this holds for both firms. From (6) it follows that the profit decreases when the firms accredit given that we are in this specific interval. Then from (8c) it is seen that the profits are highest for a simultaneous Cournot relatively to a two-stage Cournot. This means that the firms will prefer playing simultaneous Cournot to a two-step Cournot. For all other values of $\frac{\gamma_{i}-l_{i}}{\lambda_{j}}$, the simultaneous Cournot and the two-stage Cournot give the exact same solutions. A similar comparison of the two Bertrand equilibria (SB and NB) gives the opposite conclusion. Suppose now that we are in the interval when $-g^{2}<\frac{\gamma_{i}-l_{i}}{\lambda_{j}} \leq-\frac{g^{2}}{2-g^{2}}$. Then $A_{i}^{S B}=1$ and $A_{i}^{N B}=0$, implying that the profits are highest in the two-stage Bertrand game (see 9c). This means that the firms would prefer playing the two-stage Bertrand game to the simultaneous game. For all other values of $\frac{\gamma_{i}-l_{i}}{\lambda_{j}}$, the Bertrand outcomes coincide. Moreover, when it comes to a comparison between the profits of the cartel case, the Cournot and the Bertrand cases, the standard results hold. This means that cartel profits are higher than Cournot profits, which again are higher than Bertrand profits.

Our comparison of accreditation incentives across market structures demonstrates that sectors with high accreditation rates will be characterized by firms i) expecting significant increases in the willingness to pay for own accredited products, ii) having low accreditation costs, iii) operating in markets with fierce competition (price competition in substitutable goods with a high degree of product differentiation) or iv) serving markets with a high degree of coordination.

\section{Welfare analysis}

To conduct a welfare analysis, assumptions need to be made as to the extent to which becoming accredited represents an informative signal for consumers regarding product quality. To the extent accreditation represents a third-party verification of product quality, changes in consumers' willingness to pay will be based upon true quality improvements. However, evidence from the literature on possible output improvements from accreditation (see the introduction) suggests that this is not always the case. One possible interpretation is that accreditation in some cases acts as a 
third-party verification of process changes but does not necessarily inflict real product quality improvements.

In what follows, we undertake welfare analyses under two different assumptions. First, we consider the case where the increase in the consumers' willingness to pay for the products of accredited firms reflects true product quality improvements. The accreditation body verifies exact quality levels (product accreditation). Second, we consider the situation where accreditation does not yield an increase in product quality (for example if only production processes change), meaning that consumers falsely believe in product quality improvements from accreditation (consumer misperceptions). This is a possible outcome given process accreditation.

Based on the demand functions defined in (1a) and (1b) and the cost functions in (2), the total welfare, $W$, is given by the total willingness to pay, $U\left(q_{i}, q_{j}\right)$, minus total costs as defined in (10).

$$
\begin{aligned}
& W=U\left(q_{i}, q_{j}\right)-C_{i}-C_{j}=a_{i} q_{i}+a_{j} q_{j}+\beta\left[\gamma_{i} A_{i} q_{i}+\gamma_{j} A_{j} q_{j}-g \lambda_{i} A_{j} q_{i}-g \lambda_{j} A_{i} q_{j}\right]-\frac{1}{2} q_{i}^{2}- \\
& \frac{1}{2} q_{j}^{2}-g q_{i} q_{j}-\left[\left(c_{i}+l_{i} A_{i}\right) q_{i}+\left(c_{j}+l_{j} A_{j}\right) q_{j}\right]
\end{aligned}
$$

where $\beta=1$ represents the case where the increase in the consumers' willingness to pay for the products of accredited firms reflects true product quality improvements, while $\beta=0$ represents the case where accreditation does not yield any increase in product quality. ${ }^{21}$ Maximizing (10) gives us the following conditions for the welfare optimal outcome for prices, quantities and accreditation decisions, $\left(p_{i}^{W}, q_{i}^{W}, A_{i}^{W}\right), i=1,2$ :

$$
q_{i}^{W}=\frac{\omega_{i}\left(A_{i}^{W}, A_{j}^{W}\right)-(1-\beta)\left(\gamma_{i} A_{i}^{W}-g \lambda_{i} A_{j}^{W}\right)-g\left[\omega_{j}\left(A_{i}^{W}, A_{j}^{W}\right)-(1-\beta)\left(\gamma_{j} A_{j}^{W}-g \lambda_{j} A_{i}^{W}\right)\right]}{1-g^{2}}
$$

$$
\begin{aligned}
& \text { (11b) } p_{i}^{W}=c_{i}+l_{i} A_{i}^{W} \\
& \text { (11c) } \pi_{i}^{W}=0 \\
& \text { (11d) } A_{i}^{W}=1 \text { if }\left(\beta \gamma_{i}-l_{i}\right) q_{i}^{W}-g \beta \lambda_{j} q_{j}^{W}>0 \text { or } A_{i}^{W}=0 \text { if }\left(\beta \gamma_{i}-l_{i}\right) q_{i}^{W}-g \beta \lambda_{j} q_{j}^{W} \leq 0
\end{aligned}
$$

Condition (11a) defines the welfare optimal quantities dependent on the values of $\omega_{i}, \omega_{j,} \beta$ and $g$. Condition (11b) tells us, as expected, that the welfare optimal solution is characterized by prices equal to marginal costs. As prices are equal to the constant marginal cost, the firms' profits are zero, see equation (11c). Finally, condition (11d) tells us that firm $i$, from a welfare point of view, should be

\footnotetext{
${ }^{21}$ Following the specification by Matsumura and Sunada (2013) when discussing advertising, we have introduced a parameter $\beta$ reflecting the proportion of true and valuable information for consumers regarding accreditation.
} 
accredited if the sum of the direct effect from accreditation, $\left(\beta \gamma_{i}-l_{i}\right) q_{i}^{w}$, and the indirect effect from accreditation (the effect on the other market), $-g \beta \lambda_{j} q_{j}^{w}$, is positive. In the case of substitutes, the indirect effect is negative, reflecting that the loss inflicted upon market $j$ should be taken into account. In the case of complements, the indirect effect is positive, reflecting a benefit in market $j$ that is to be taken into account by firm $i$.

Let us first consider the case where $\beta=1$, i.e. firm accreditation represents valuable information for the consumers. Then it follows from (11d) that accreditation is welfare improving in market $i$ if $\frac{\gamma_{i}-l_{i}}{\lambda_{j}}>g \frac{q_{j}^{W}}{q_{i}^{W}}$, otherwise it is not. It is seen that the higher the effect accreditation has on the marginal willingness to pay in market $i, \gamma_{i}$, the lower the cost increase that follows from accreditation for firm $i, l_{i}$, and the lower the effect accreditation in market $\mathrm{i}$ has on the willingness to pay in market $\mathrm{j}, \lambda_{j}$, the higher is the probability that accreditation in market $i$ is welfare improving. Moreover, in the case of substitutes, the higher the value of $g$, the lower is the probability for accreditation to be socially desirable. In the case of complements, the probability for accreditation being socially desirable increases as $g$ approaches -1 .

Given $\beta=1$, the different intervals of the factor $\frac{\gamma_{i}-l_{i}}{\lambda_{j}}$, determining when accreditation decisions are welfare optimal, coincide with the intervals already identified for cartel firms [see (s1)-(s6) and (c1)(c6)], i.e. $g \frac{q_{j}^{W}}{q_{i}^{W}}=g \frac{\omega_{j}-g \omega_{i}}{\omega_{i}-g \omega_{j}}=g \frac{q_{j}^{K}}{q_{i}^{K}}$. This implies that the accreditation status of cartel firms always is welfare optimal. Given this, the social desirability of the Cournot and Bertrand markets can easily be evaluated from Figure 1 and Figure 2 by replacing $g \frac{q_{j}^{K}}{q_{i}^{K}}$ with $g \frac{q_{j}^{W}}{q_{i}^{W}}$. In doing this, it follows that accreditation is socially preferable when $\frac{\gamma_{i}-l_{i}}{\lambda_{j}}>g \frac{q_{j}^{W}}{q_{i}^{W}}=g \frac{q_{j}^{K}}{q_{i}^{K}}$. For substitutes (see Figure 1 ), the competitive markets (simultaneous - and two-stage games) produce too strong accreditation incentives relative to what is socially preferable, and this problem is more significant in Bertrand markets relative to Cournot markets. As the products become more substitutable, in the sense that $g$ approaches 1 , the difference between the socially preferable outcome and the actual outcome for the two competitive markets will increase. For complements (see Figure 2), on the other hand, the two competitive markets produce accreditation incentives being too weak compared with what is socially preferable; this problem is more significant for Cournot markets than for Bertrand markets.

Next, we move on to studying the welfare optimal solution when accreditation does not produce true product quality improvements (consumer misperceptions) $(\beta=0)$. It follows from (11d) that 
$A_{i}^{W}=1$ if $-l_{i} q_{i}^{W}>0$ and $A_{i}^{W}=0$ if $-l_{i} q_{i}^{W} \leq 0$. Now accreditation, both for substitutes and complements, is welfare improving only if accreditation is cost-reducing. This finding has several implications. First, the accreditation status of cartel firms may now deviate from the welfare optimal solution. Now cartel firms, given a societal perspective, have too strong incentives for seeking accreditation. Second, in the case of substitutes, the problem of accreditation incentives being too strong in competitive markets is further reinforced. Third, in the case of complements, the problem of accreditation incentives being too weak in competitive markets is changed into a situation producing too strong incentives.

In comparing the overall welfare from the different market solutions in sections 3 and 4 , both the influence from the accreditation - and quantity decisions in the various cases must be considered. For instance, suppose now that accreditation reflects true quality improvements. In this case the cartel solution secures a welfare optimal solution when it comes to accreditation choices. However, by comparing (7a) and (11a) it is evident that the quantities supplied by the cartel are exactly half of the welfare optimal quantities and thus affecting consumer surpluses and overall welfare negatively. The Bertrand and Cournot cases produce higher quantities than the cartel, affecting overall welfare positively, but could also imply that the firms have chosen to accredit in situations when it is welfaredecreasing. Hence, in order to make a welfare ranking of the different competitive market outcomes, one has to weigh the possible welfare losses concerning too high accreditation incentives against possible welfare gains obtained by higher quantities. It should be noticed that in such comparisons, for given levels of accreditation, the well-known result that the Bertrand outcome is preferred to the Cournot outcome from a welfare point of view, holds.

\section{Extensions}

In this section we extend the basic model in three different directions; a continuous accreditation decision, general demand and cost functions, and multi-firm competition ( $n$-firms).

\subsection{Accreditation as a continuous variable and quadratic cost functions}

In some cases accreditation needs not include an entire institution. One example is educational institutions seeking accreditation status for individual units or separate programmes (e.g. professional education). In the following we consider the case where the accreditation decision is a continuous variable. In the basic model, since accreditation is a binary decision (accreditation or nonaccreditation), it works well with a linear cost function. However, now, since studying accreditation 
as a continuous variable, strictly concave profit functions are needed. In the literature, quadratic cost functions are common (see e.g. Hattori and Higashida, 2012). By replacing the linear cost functions of the basic model (see equation (2)), with a quadratic specification of the following type, $C_{i}=\left(c_{i}+\right.$ $\left.k_{i} A_{i}^{2}\right) q_{i}$, equation (4) becomes as follows; $\omega_{i}=a_{i}-c_{i}+A_{i}\left(\gamma_{i}-k_{i} A_{i}\right)-g \lambda_{i} A_{j}$.

It is now possible to calculate the optimal degree (intensity) of accreditation for all market solutions and the welfare optimal case. It follows that

$$
\begin{aligned}
& A_{i}^{S C}=\frac{\gamma_{i}}{2 k_{i}}<A_{i}^{N C}=\frac{\gamma_{i}}{2 k_{i}}+\frac{g^{2} \lambda_{j}}{4 k_{i}}<A_{i}^{N B}=\frac{\gamma_{i}}{2 k_{i}}+\frac{g^{2} \lambda_{j}}{\left(4-2 g^{2}\right) k_{i}}<A_{i}^{S B}=\frac{\gamma_{i}}{2 k_{i}}+\frac{g^{2} \lambda_{j}}{2 k_{i}} \\
& A_{i}^{W}=A_{i}^{K}=\frac{\gamma_{i}}{2 k_{i}}-\frac{g \lambda_{j}}{2 k_{i}} \frac{q_{j}}{q_{i}}
\end{aligned}
$$

From (12a) and (12b) we observe that the structure of the firms' incentives to accredit coincides with the structure already identified when portraying accreditation as a binary variable (see sections 3 and 4). First, it is observed that the higher value of $\gamma_{i}$ and the lower $k_{i}$, the higher is the optimal accreditation intensity for all cases. Second, for two-stage Cournot (NC), two-stage Bertrand (NB), and simultaneous Bertrand (SB), the optimal accreditation intensity increases in the absolute value of $g$ and the size of $\lambda_{j}$. Third, from (12a) we see that highest accreditation rate (intensity) is attained for simultaneous Bertrand (SB), followed by two-stage Bertrand (NB), two-stage Cournot (NC) and simultaneous Cournot (SC). From (12b), we observe that the cartel (K) chooses a welfare optimal accreditation intensity (when accreditation provides a true quality-improvement). Furthermore, it is straightforward to show that for substitutes, all competing firms choose a too high accreditation intensity, while for complements, all competing firm choose a too low accreditation intensity. The above findings coincide with the findings arrived at for the basic model thus the nature of the decision variable (binary or continuous) does not impact our main findings.

\subsection{General functions for demand and costs}

Getting accredited affects the marginal production costs since compliance with standards and requirements is resource-demanding. In our model set-up, the cost of accreditation is represented by additive elements in the cost function. Such an approach is also taken in the works on advertisement referred to in Section 1. The cost functions and the demand functions are linear in the basic model. The linear demand follows from a utility function specified by Singh and Vives (1984) (see also Häckner, 2000 and Garella and Petrakis, 2008). According to Cheng (1985), results concerning Cournot and Bertrand solutions following from linear functions typically hold for fairly general and reasonable assumptions regarding demand and cost functions. In the following, we extend our basic 
model by introducing general demand and cost functions to study if such a change produce new conclusions.

Let the demand functions on price and quantity forms be given by $p_{i}=p_{i}\left(q_{i}, q_{j}, A_{i}, A_{j}\right)$, where $\frac{\partial p_{i}}{\partial q_{i}}<0, \frac{\partial p_{i}}{\partial A_{i}}>0, \frac{\partial p_{i}}{\partial q_{j}}<(>) 0$ and $\frac{\partial p_{i}}{\partial A_{j}}<(>) 0$ for substitutes (complements) and $q_{i}=$ $q_{i}\left(p_{i}, p_{j}, A_{i}, A_{j}\right)$ where $\frac{\partial q_{i}}{\partial p_{i}}<0, \frac{\partial q_{i}}{\partial A_{i}}>0, \frac{\partial q_{i}}{\partial p_{j}}<(>) 0$ and $\frac{\partial q_{i}}{\partial A_{j}}<(>) 0$ for substitutes (complements) $^{22}$. Furthermore, let the cost functions be as follows; $C_{i}=C_{i}\left(q_{i}, A_{i}\right)$ where $\frac{\partial C_{i}}{\partial q_{i}}>0$, $\frac{\partial C_{i}}{\partial A_{i}}>0$. It can now be shown that the various equilibria for the five markets structures are given by the following conditions;

$$
\begin{aligned}
& A_{i}^{S C}=1\left(A_{i}^{S C}=0\right) \text { if } \frac{d \pi_{i}}{d A_{i}}=\frac{\partial p_{i}}{\partial A_{i}} q_{i}^{C}-\frac{\partial C_{i}}{\partial A_{i}}>(\leq) 0 \\
& A_{i}^{N C}=1\left(A_{i}^{N C}=0\right) \text { if } \frac{d \pi_{i}}{d A_{i}}=\frac{\partial p_{i}}{\partial A_{i}} q_{i}^{C}-\frac{\partial C_{i}}{\partial A_{i}}+\frac{\partial p_{i}}{\partial q_{j}} \frac{\partial q_{j}^{C}}{\partial A_{i}}>(\leq) 0 \\
& A_{i}^{S B}=1\left(A_{i}^{S B}=0\right) \text { if } \quad \frac{d \pi_{i}}{d A_{i}}=\left(p_{i}-\frac{\partial C_{i}}{\partial q_{i}}\right) \frac{\partial q_{i}}{\partial A_{i}}-\frac{\partial C_{i}}{\partial A_{i}}=\frac{\frac{\partial q_{i}}{\partial A_{i}}}{\frac{\partial q_{i}}{\partial p_{i}}} q_{j}^{B}-\frac{\partial C_{i}}{\partial A_{i}}>(\leq) 0 \\
& A_{i}^{N B}=1\left(A_{i}^{N B}=0\right) \text { if } \frac{d \pi_{i}}{d A_{i}}=\left(p_{i}-\frac{\partial C_{i}}{\partial q_{i}}\right) \frac{\partial q_{i}}{\partial A_{i}}-\frac{\partial C_{i}}{\partial A_{i}}+\left(p_{i}-\frac{\partial C_{i}}{\partial q_{i}}\right) \frac{\partial q_{i}}{\partial p_{j}} \frac{\partial p_{j}^{B}}{\partial A_{i}}>(\leq) 0 \\
& A_{i}^{K}=1\left(A_{i}^{K}=0\right) \quad \text { if } \quad \frac{d\left(\sum_{i} \pi_{i}\right)}{d A_{i}}=\frac{\partial p_{i}}{\partial A_{i}} q_{i}^{K}-\frac{\partial C_{i}}{\partial A_{i}}+\frac{\partial p_{j}}{\partial A_{i}} q_{j}^{K}>(\leq) 0
\end{aligned}
$$

First, consider the two Cournot games (see 13ab). For substitutes (complements) the cartel (K) produces lower (higher) accreditation incentives relatively to the Cournot games (SC and NC). The condition for SC (see 13a) differs from the condition for NC (see 13b) due to the presence of the element $\frac{\partial p_{i}}{\partial q_{j}} \frac{\partial q_{j}^{C}}{\partial A_{i}}$ in (13b). This term is, given our assumptions, strictly positive, hence the incentive for seeking accreditation is always higher for SC relatively to NC (both for substitutes and complements). Consequently, the ranking of $\mathrm{K}, \mathrm{SC}$ and $\mathrm{NC}$ coincides with what we arrived at for the basic model. A similar reasoning can now be applied for the cartel $(K)$ and the two Bertrand games (see (13c) and (13d)). Again the cartel (K) produces lower (higher) accreditation incentives relatively to the two Bertrand games for substitutes (complements). The condition for (13c) differs from (13d) due to the

\footnotetext{
${ }^{22}$ Here we have implicitly assumed that the demand functions are "well defined", either whether we specify the functions on price or quantity forms, i.e. presume that the inverse functions globally exist.
} 
presence of the element $\left(p_{i}-\frac{\partial C_{i}}{\partial q_{i}}\right) \frac{\partial q_{i}}{\partial p_{j}} \frac{\partial p_{j}^{B}}{\partial A_{i}}$ in (13d). This term is, given our assumptions, strictly positive, hence the incentive for seeking accreditation is higher for SB relatively to NB (both for substitutes and complements). Again, we can conclude that the ranking of K, SB and NB coincide with the same ranking arrived at for the basic model. The condition for arriving at a complete ranking being similar to the ranking arrived at for the basic model is that the accreditation incentive produced by (13d) is higher than the accreditation incentive produced by (13b). However, such a condition is not fulfilled with necessity, thus we cannot, for general demand and cost functions, rule out the possibility that the two Bertrand games produce lower (higher) accreditation incentives relatively to the two Cournot for substitutes (complements).

\subsection{Multi-firm competition}

The basic model is limited to include the accreditation incentives for two competing firms (duopoly). However, a higher number of firms might influence the accreditation incentives via market demand effects (accreditation costs will be unchanged). A higher number of competitors might reduce the strength of accreditation as a signal in own market as well as weakening the effect that accreditation has on willingness to pay in other markets. ${ }^{23}$ In order to analyse the role of multi-firm competition we will now consider a generalized case of the linear cost and demand case by Singh and Vives (1984). In doing so, we follow the approach taken by Matsumoto and Szidarovszky (2010). First, let $n$ denote the number of firms. Second, let the demand function now be defined as follows; $p_{i}=a_{i}-$ $q_{i}-g \sum_{j \neq i}^{n} q_{j}+\gamma_{i} A_{i}-g \lambda_{i} \sum_{j \neq i}^{n} A_{j}$. We then arrive at the following expressions for the optimal accreditation decision in each of the five market cases; ${ }^{24}$

$$
\begin{aligned}
& \text { (14a) } A_{i}^{S C}=1\left(A_{i}^{S C}=0\right) \text { if } \frac{\gamma_{i}-l_{i}}{\sum_{j \neq i} \lambda_{j}}>(\leq) 0 \\
& \text { (14b) } A_{i}^{N C}=1\left(A_{i}^{N C}=0\right) \text { if } \frac{\gamma_{i}-l_{i}}{\sum_{j \neq i} \lambda_{j}}>(\leq)-\frac{g^{2}}{2(1-g)+n g} \\
& \text { (14c) } A_{i}^{S B}=1\left(A_{i}^{S B}=0\right) \text { if } \frac{\gamma_{i}-l_{i}}{\sum_{j \neq i} \lambda_{j}}>(\leq)-\frac{g^{2}}{1+(n-2) g} \\
& \text { (14d) } A_{i}^{N B}=1\left(A_{i}^{N B}=0\right) \text { if } \frac{\gamma_{i}-l_{i}}{\sum_{j \neq i} \lambda_{j}}>(\leq)-\frac{g^{2}(1+(n-2) g)}{(2+(n-3) g)(1+(n-1) g)-g(1+(n-2) g)} \\
& \text { (14e) } A_{i}^{K}=1\left(A_{i}^{K}=0\right) \quad \text { if } \frac{\gamma_{i}-l_{i}}{\sum_{j \neq i} \lambda_{j}}>(\leq) \frac{\sum_{j \neq i} q_{j}^{K}}{q_{i}^{K}} g
\end{aligned}
$$

\footnotetext{
${ }^{23}$ Such an effect is pointed out in a similar model by Garella and Petrakis (2008) addressing minimum quality standards.

${ }^{24}$ For a discussion of necessary and sufficient conditions for existence and stability of the different equilibria we refer to Matsumoto and Szidarovszky (2010).
} 
By comparing the conditions in (14a-e) with the corresponding conditions in section 3 and 4, we see that our findings correspond well to the results for the two-firm case (see also Figure 1 and Figure 2 in section 5). In order to see how the number of firms and markets $(n)$ affects accreditation incentives, suppose that the demand and cost functions are identical for all firms, i.e. parameters $\gamma, l, \lambda$ are identical across firms. Having Figure 1 and Figure 2 in mind, it is easily seen that the limits for choosing accreditation move to the right for all competitive market types as $n$ increases. Moreover, in the case of cartel, the limit for accreditation moves to the right in the case of substitutes, while it moves to the left for the case of complements. This means that the accreditation incentives for each market type become weaker when the number of identical firms increase. As $n$ increases, the incentive for the cartel to seek accreditation weakens in the case of substitutes, while it becomes stronger in the case of complements. This implies that the welfare optimal limits are also affected by the number of firms.

\section{Conclusion}

To our knowledge no former study has analysed accreditation incentives in duopoly markets. Based on the relatively extensive occurrence of accreditation in many industries, we have therefore found it interesting to formulate a model in order to study accreditation incentives under different competitive environments. Independent of market structure: i) the higher the marginal increase in the willingness to pay for own product following from becoming accredited and ii) the lower the change in production costs that accrues from becoming accredited, the higher the incentives for seeking accreditation. Furthermore, for a given degree of product differentiation, the effect that the own accreditation decision may have on the willingness to pay for rival's product as well as the effect the rival's accreditation decision may have on the willingness to pay for own product, have an impact. Finally, we find that the degree of competition (type of market structure) is important for accreditation incentives.

Given substitutes, the incentives for seeking accreditation increase with the degree of market competition. Hence, firms in Bertrand competition face stronger incentives than firms in Cournot competition, which in turn face stronger incentives than the cartel situation. Simultaneous Bertrand gives the highest incentive to seek accreditation, while simultaneous Cournot provides the lowest incentives to accredit. The degree of product differentiation may reflect the degree of competition for substitutable goods and we find that, as the products become closer to perfect substitutes, the lower the incentives for cartel firms to seek accreditation and the higher the incentives for Cournot 
firms and Bertrand firms to seek accreditation. Given complements, the above conclusions change. Now, the incentives for seeking accreditation are highest for cartel firms, followed by Bertrand firms, and then Cournot firms. Moreover, as the products become closer to perfect complements, the incentives for seeking accreditation increase in all markets.

The model is extended in three directions. For continuous accreditation decisions with quadratic cost functions and in multi-firm competition, we do not arrive at qualitative new conclusions. For general demand and cost functions, the ranking of the cartel and the two Cournot models and the ranking of the cartel and the two Bertrand models is the same. We are, however, not able to rule out the possibility that the two Bertrand games produce lower (higher) accreditation incentives relatively to the two Cournot for substitutes (complements).

We have chosen to deduce two different welfare optimal solutions. First, we consider the case where the increase in the consumers' willingness to pay for accredited products represents true valuations, and find that the accreditation decisions of cartel firms coincide with the welfare optimal one. In the case of substitutes, competitive firms (Bertrand and Cournot competition) face too strong accreditation incentives relative to what is socially preferable, and this tendency is being reinforced as the goods become more substitutable. For complements, Bertrand and Cournot firms face accreditation incentives that are too weak compared with what is socially preferable, and this problem is being reduced as the goods become more coordinated. Second, we consider the case where the increase in the consumers' willingness to pay for the products of accredited firms is based upon consumer misperceptions. Given this, all firms, independent of market structure, face too strong accreditation incentives compared with what is socially preferable. Now, accreditation is socially optimal only if the process of becoming accredited causes a reduction in firms' production costs. To sum up, in the case of substitutes, the competitive markets imply too high incentives for accreditation, while in the case of complements the incentives are too low from a welfare perspective. Consequently, when firms consider the positive and negative effects on own demand by rival accreditation decision, we have a strategic situation that may cause accreditation games of the types addressed in our analysis.

Our model, adopting a framework first used by Singh and Vives (1984), assumes an exogenous degree of differentiation. However, in reality it might be that the degree of product differentiation is affected by the accreditation decision itself. In other words, a firm may choose to seek accreditation to reduce the interdependency between the markets and thereby improve its market power. Second, our model does not include the case where the market is of a given size, forcing the firms to play a 
zero-sum game in market shares. Modelling such a market most likely leads to a more aggressive "race for accreditation" since a firm's optimal response will be to eliminate (partly or totally) the initial advantage the rival achieves by seeking accreditation. Such an outcome, however, appears less likely for product accreditation than for process accreditation, since product accreditation reveals the true quality type, while process accreditation does not. Third, our analysis presumes that the competing firms are informed about how demand and technology of the rival are affected by accreditation (determining the rivals' product quality). An alternative would be to undertake an analysis where quality and costs are private information, thus making the effects stemming from accreditation uncertain. If so, firms' accreditation incentives will most likely be weakened.

Our findings add to the advertising and disclosure literature by including both Cournot markets and complementary products. Furthermore, our results nuance the common conclusion in the disclosure literature that a higher degree of (price) competition decreases disclosure. However, further theoretical and empirical research will allow us to understand firms' motives and rationales to explain the relatively high occurrence of quality requirements by accreditation in some industries.

\section{References}

Albano, G. L., and Lizzeri, A. (2001). Strategic certification and provision of quality. International Economic Review, 42(1), 267-283.

Anderson, S. W., Daly, J. D., and Johnson, M. F. (1999). Why firms seek ISO 9000 certification: Regulatory compliance or competitive advantage? Production and Operations Management, 8(1), 2843.

Bagwell, K. (2007). The economic analysis of advertising. In M. Armstrong and R. Porter (Eds.), Handbook of Industrial Organization (Vol. 3, pp. 1701-1844). Amsterdam: North Holland.

Barker, K. N., Flynn, E. A., Pepper, G. A., Bates, D. W., and Mikeal, R. L. (2002). Medication errors observed in thirty-six health care facilities. Archives of Internal Medicine, 162(16), 1897-1903.

Benson, T. E. (1991). Quality goes international. Industry Week, 240(16), 54-57.

Board, O. (2009). Competition and disclosure. The Journal of Industrial Economics, 57(1), 197-213.

Braithwaite, J., Westbrook, J., Pawsey, M., Greenfield, D., Naylor, J., Ledema, R., . . Gibberd, R. (2006). A prospective, multi-method, multi-disciplinary, multi-level, collaborative, socialorganisational design for researching health sector accreditation. BMC Health Services Research, 6. doi:10.1186/1472-6963-6-113

Caldieraro, F., Shin, D., and Stivers, A. (2011). Voluntary quality disclosure under price-signaling competition. Managerial and Decision Economics, 32(8), 493-504. doi:10.1002/mde.1550 
Chen, J., Rathore, S. S., Radford, M. J., and Krumholz, H. M. (2003). Accreditation and quality of care for acute myocardial infarction. Health Affairs, 22(2), 243-254.

Cheng, L. (1985). Comparing Bertrand and Cournot Equilibria: A Geometric Approach. RAND Journal of Economics, 16(1), 146-152.

Cheong, I., and Kim, J. Y. (2004). Costly information disclosure in oligopoly. Journal of Industrial Economics, 52(1), 121-132. doi:10.1111/j.0022-1821.2004.00218.x

Corbett, C. J., Montes, M. J., Kirsch, D. A., and Alvarez-Gil, M. J. (2002). Does ISO 9000 certification pay. ISO Management Systems, 2(4), 31-40.

Corcoran, C. P. (2007). Distinctions among accreditation agencies for business programs. Journal of College Teaching and Learning, 4(9), 27-30.

Dranove, D., and Jin, G. Z. (2010). Quality disclosure and certification: Theory and practice. Journal of Economic Literature, 48(4), 935-963.

Dye, R. A., and Sridhar, S. S. (1995). Industry-wide disclosure dynamics. Journal of Accounting Research, 33(1), 157-174. doi:10.2307/2491297

Ferguson, W. (1996). Impact of the ISO 9000 series standards on industrial marketing. Industrial Marketing Management, 25(4), 305-310.

Garella, P. G., and Petrakis, E. (2008). Minimum quality standards and consumers' information. Economic Theory, 36(2), 283-302. doi:10.1007/s00199-007-0269-9

Glaeser, E. L., and Ujhelyi, G. (2010). Regulating misinformation. Journal of Public Economics, 94(3-4), 247-257. doi:10.1016/j.jpubeco.2010.01.001

Greenfield, D., and Braithwaite, J. (2008). Health sector accreditation research: A systematic review. International Journal for Quality in Health Care, 20(3), 172-183. doi:10.1093/intqhc/mzn005

Grepperud, S. (2015). Is the hospital decision to seek accreditation an effective one? International Journal of Health Planning and Management, 30(1), E56-E68. doi:10.1002/hpm.2263

Griffith, J. R., Knutzen, S. R., and Alexander, J. A. (2002). Structural versus outcomes measures in hospitals: A comparison of Joint Commission and Medicare outcomes scores in hospitals. Quality management in health care, 10(2), 29-38.

Grossman, S. J., and Hart, O. D. (1980). Disclosure laws and takeover bids. The Journal of Finance, 35(2), 323-334. doi:10.2307/2327390

Guo, L., and Zhao, Y. (2009). Voluntary quality disclosure and market interaction. Marketing Science, 28(3), 488-501. doi:10.1287/mksc.1080.0418

Hattori, K., and Higashida, K. (2012). Misleading advertising in duopoly. Canadian Journal of Economics, 45(3), 1154-1187. doi:10.1111/j.1540-5982.2012.01730.x

Hotz, V. J., and Xiao, M. (2013). Strategic information disclosure: The case of multiattribute products with heterogeneous consumers. Economic Inquiry, 51(1), 865-881. doi:10.1111/j.1465-

7295.2010.00340.x 
Hvide, H. K., and Heifetz, A. (2001). Free-entry equilibrium in a market for certifiers.

Häckner, J. (2000). A note on price and quantity competition in differentiated oligopolies. Journal of Economic Theory, 93(2), 233-239.

Janssen, M. C. W., and Roy, S. (2015). Competition, disclosure and signalling. Economic Journal, 125(582), 86-114. doi:10.1111/ecoj.12110

Jin, G. Z. (2005). Competition and disclosure incentives: An empirical study of HMOs. RAND Journal of Economics, 36(1), 93-112.

Jovanovic, B. (1982). Truthful disclosure of information. The Bell Journal of Economics, 13(1), 36-44. doi:10.2307/3003428

Levin, D., Peck, J., and Ye, L. (2009). Quality disclosure and competition. The Journal of Industrial Economics, 57(1), 167-196.

Lizzeri, A. (1999). Information revelation and certification intermediaries. RAND Journal of Economics, $30(2), 214-231$.

Marquardt, D. W. (1992). ISO 9000: A universal standard of quality. Management Review, 81(1).

Matsumoto, A. and Szidarovszky, F. (2010). Price and Quantity Competition in Differentiated Oligopoly Revisited. Working paper.

Matsumura, T., and Sunada, T. (2013). Advertising competition in a mixed oligopoly. Economics Letters, 119(2), 183-185. doi:10.1016/j.econlet.2013.02.021

Miao, C.-H. (2009). Competition in quality standards. Journal of Industrial Economics: Notes, 57(1).

Milgrom, P. R. (1981). Rational expectations, information acquisition, and competitive bidding. Econometrica, 49(4), 921-943. doi:10.2307/1912511

Motwani, J., Kumar, A., and Cheng, C. H. (1996). A roadmap to implementing ISO 9000. International Journal of Quality and Reliability Management, 13(1), 72-83. doi:10.1108/02656719610108332

Mumford, V., Greenfield, D., Hogden, A., Forde, K., Westbrook, J., and Braithwaite, J. (2015). Counting the costs of accreditation in acute care: An activity-based costing approach. BMJ Open, $5(\mathrm{e} 008850)$.

Shapiro, C. (1986). Investment, moral hazard, and occupational licensing. The Review of Economic Studies, 53(5), 843-862.

Shaw, C. D. (2001). External assessment of health care. British Medical Journal, 322(7290), 851-854.

Shaw, C. D. (2003). Evaluating accreditation. International Journal for Quality in Health Care, 15(6), 455-456. doi:10.1093/intqhc/mzg092

Shaw, C. D. (2006). Accreditation in European health care. Joint Commission Journal on Quality and Patient Safety, 32(5), 266-275. 
Singh, N., and Vives, X. (1984). Price and quantity competition in a differentiated duopoly. The Rand Journal of Economics, 15(4), 546-554.

Sprague, L. (2005). Hospital oversight in Medicare: Accreditation and deeming authority. NHPF issue brief / National Health Policy Forum, George Washington University(802), 1-15.

Stivers, A. E. (2004). Unraveling of information: Competition and uncertainty. Topics in Theoretical Economics, 4(1).

Terlaak, A., and King, A. A. (2006). The effect of certification with the ISO 9000 Quality Management Standard: A signaling approach. Journal of Economic Behavior and Organization, 60(4), 579-602. doi:10.1016/j.jebo.2004.09.012

van Damme, D. (2004). Standards and indicators in institutional and programme sccreditation in higher rducation: A conceptual framework and a proposal. In L. Vlasceanu and L. C. Barrows (Eds.), Indicators for Institutional and Programme Accreditation in Higher/Tertiary Education (pp. 125-157). Bucharest: UNESCO-CEPES.

Viscusi, W. K. (1978). A note on "lemons" markets with quality certification. The Bell Journal of Economics, 9(1), 277-279. doi:10.2307/3003627

Vlãsceanu, L., Grünberg, L., and Parlea, D. (2004). Quality assurance and accreditation (Unesco-Cepes Papers). Bucharest.

Whitebook, M., Sakai, L. M., and Howes, C. (2004). Improving and sustaining center quality: The role of NAEYC accreditation and staff stability. Early Education and Development, 15(3), 305-326.

Woodhead, A. (2013). Scoping medical tourism and international hospital accreditation growth. International Journal of Health Care Quality Assurance, 26(8), 688-702. doi:10.1108/IJHCQA-10-20110060

Woolston, P. J. (2012). The costs of institutional accreditation: A study of direct and indirect costs. (Doctor of education), University of Southern California.

Xiao, M. (2010). Is quality accreditation effective? Evidence from the childcare market. International Journal of Industrial Organization, 28(6), 708-721.

\section{Figure captions}

Figure 1. Accreditation incentives for substitutable products $(g>0)$.

Figure 2. Accreditation incentives for complementary products $(g<0)$. 
Figure 1

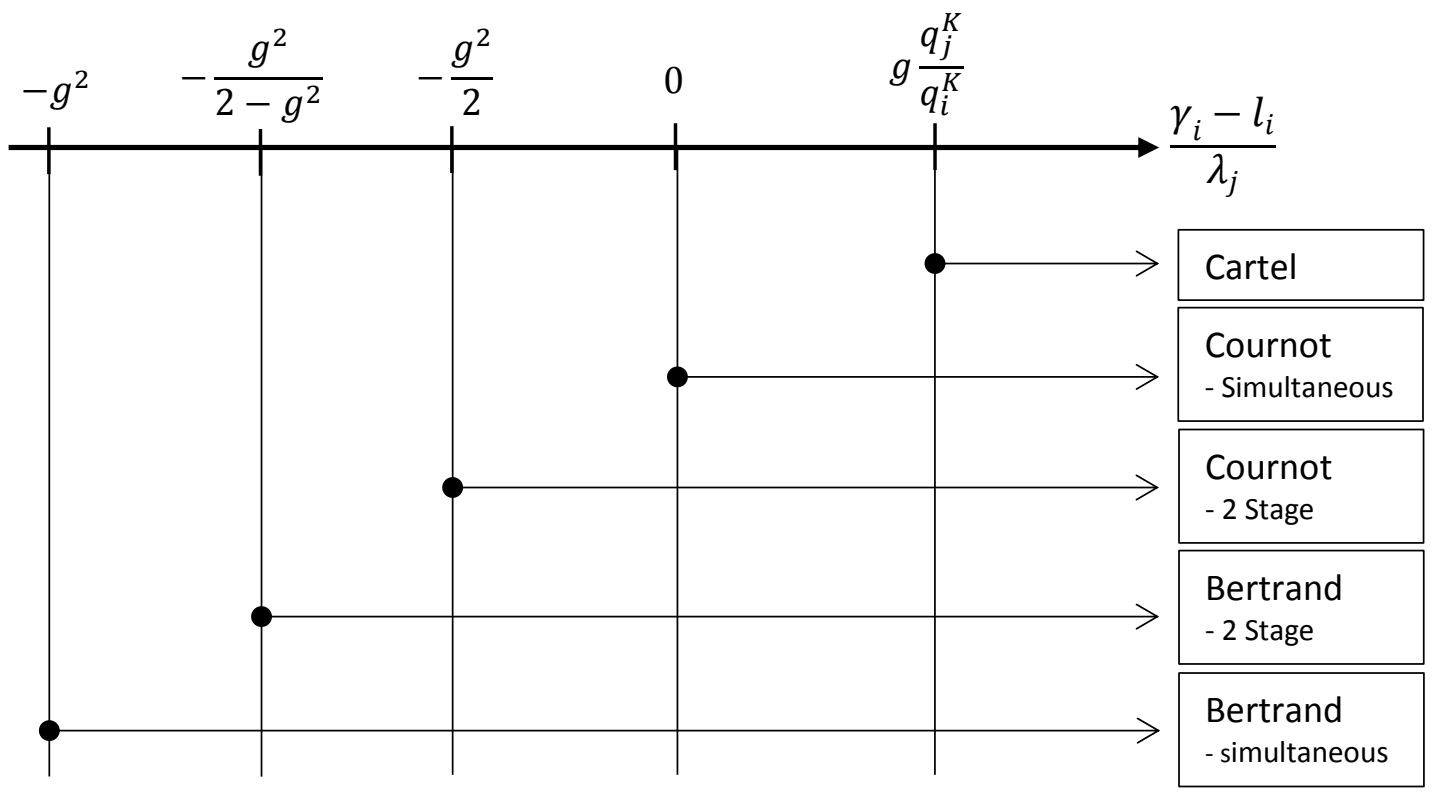


Figure 2

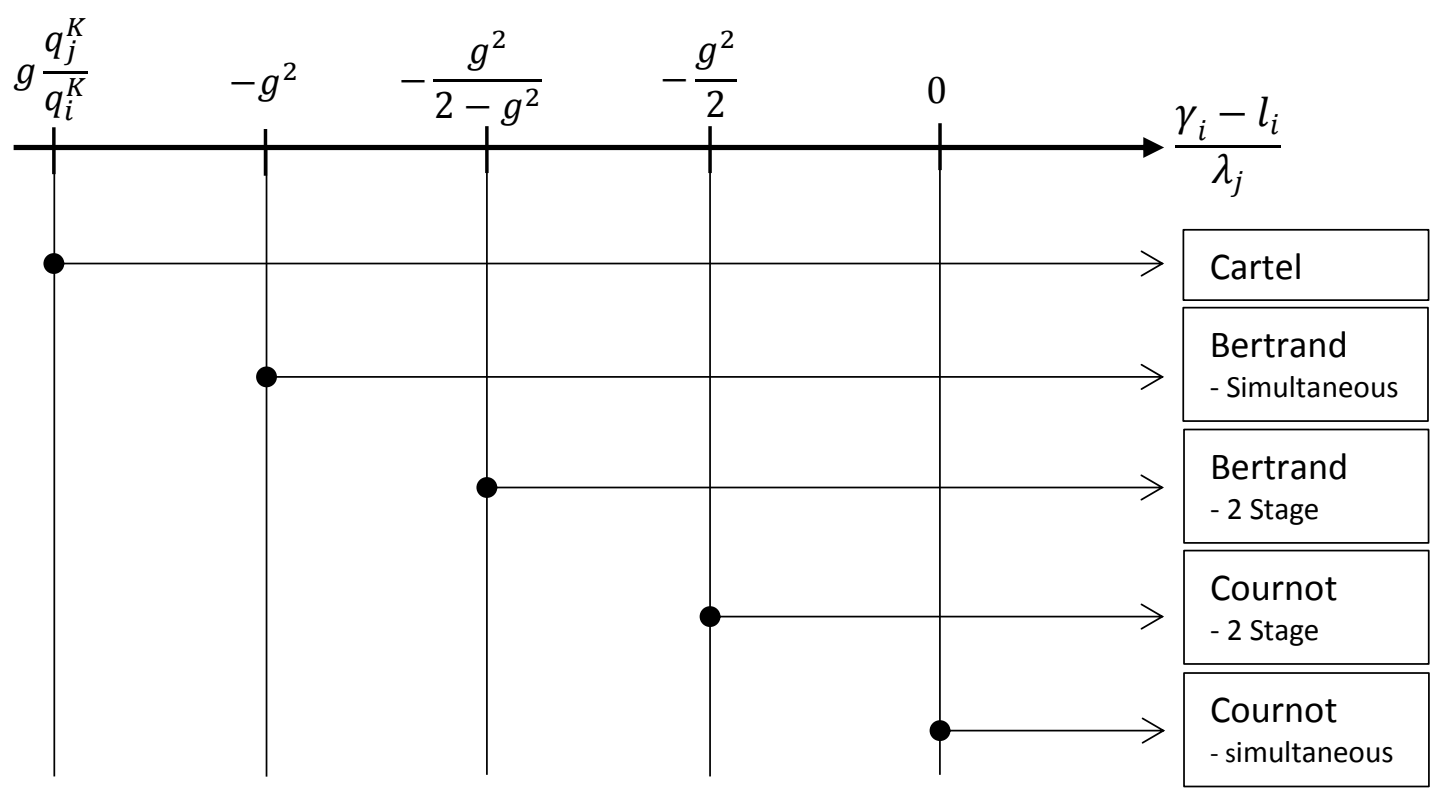

